\title{
DEL ESPACIO PÚBLICO PLANEADO A LOS ESPACIOS PÚBLICOS VIVOS Y VIVIDOS: Reflexión sobre la planificación de los espacios públicos en Bogotá
}

\author{
Laura Inés Oliveros Amaya \\ Pontificia Universidad Javeriana \\ Director de la investigación: Jean-François Jolly \\ oliveroslaura@javeriana.edu.co
}

\section{RESUMEN}

El espacio público juega un papel fundamental en la ciudad. La forma en que se ha pensado este lugar, cómo se ha planificado y cómo es utilizado por los habitantes influye directamente en la forma que toma la ciudad. Este artículo, se presenta como un avance a la investigación desarrollada en el marco de la Maestría en Planeación Urbana y Regional de la Pontificia Universidad Javeriana. En ella se plantea que las grandes transformaciones que han sufrido el espacio público en los últimos años, como la segregación, privatización y choque en formas de apropiación han dado cuenta de la necesidad de replantear la forma en que se piensan y se planean los espacios públicos. Tomando como caso de estudio la ciudad de Bogotá, se argumenta que es necesario entender con mayor profundidad las prácticas urbanas, que se desarrollan en ellos y complejizar la forma en que se estudian, permitiendo una mirada plural y multifuncionalidad a ese gran espacio articulador en la ciudad.

Palabras clave: planeación urbana, espacio público y prácticas urbanas

\begin{abstract}
Public space has an important role within the city. The way it has thought, planned and used by the inhabitants has a direct influence in the city from. This article presents the progress that has this as an academic research as a student from the master program on Urban and Regional Planning at the Pontificia Universidad Javeriana. In this article, starts by recognizing that cities have suffered significant transformations, that has led to problems such as segregation, privatization and fights in forms of uses. For such reason, it is acknowledged the necessity of rethink how public space in planned in cities. Taking Bogota as a case study, it is argued that there is a need to understand urban social practices in a deepest way, where planning should take a plural and multifunctional look when is talked about public spaces in cities.
\end{abstract}

Key Words: Urban planning, public space and urban practices 


\section{INTRODUCCIÓN}

El espacio público juega un papel fundamental en la ciudad. La forma en que se ha pensado este lugar, cómo se ha planificado y cómo es utilizado por los habitantes influye en la conformación de ese gran complejo denominado ciudad. Tradicionalmente, al espacio púbico se le han atribuido unas características estáticas e inamovibles. Se habla de un lugar que permite la interacción entre personas, donde existe la diferencia, el respecto y el conflicto conviven permanentemente, en donde se conjugan los intereses de los transeúntes, donde predomina el anonimato y finalmente el lugar que le da la esencia a la vida urbana.

Sin embargo, esta visión del espacio público puede llegar un ser un poco romántica cuando se trata de visualizar la realidad en las ciudades. Los cambios en la economía, los cambios sociales acelerados han producido grandes transformaciones en la vida de las ciudades, lo cual ha generado diferentes problemáticas. En palabras de María Fabiola Pardo (2008: 68) "la suburbanización, la polarización socio-cultural, la segregación residencial y la fragmentación aparecen como los aspectos distintivos del nuevo tipo de ciudad emergente". Quien luego argumenta que estos hechos han modificado profundamente el rol de los espacios públicos dentro de las ciudades, y la forma en que los habitantes se apropian de este. De esta forma, autores como Jordi Borja (2003), Zaida Muxi (2003), Fernando Sabatini (2005), Emilio Duhau (2008), han expuesto la necesidad de realizar una mirada más cautelosa a "las nuevas dinámicas urbanas y elaborar respuestas a los desafíos que nos planteamos desde la perspectiva del espacio público" (Borja \& Muxi, 2003: 27).

Bajo esta línea, Bogotá una ciudad con casi ocho millones de habitantes no es ajena a esta realidad. Se pueden encontrar conjuntos cerrados que desconectan la trama y el tejido de la ciudad, proliferación de centros comerciales, choque de usos por la apropiación de parte de vendedores ambulantes que encontraron un lugar de trabajo, lugares inseguros, y dificultad en la movilidad versus grandes infraestructuras como parques y plazas que no parecen estar siendo utilizados por la mayoría. Donde el espacio público se fragmenta cada vez más y en donde la visión de la planeación parece no articularse con la realidad. Aunque, tal fenómeno como la "muerte de los espacios públicos", no esté presente, sí se hace evidente las transformaciones que comienzan a ser evidentes en el espacio público de la ciudad. Por lo tanto, esta investigación está interesada en realizar una reflexión sobre la relación entre la planificación del espacio público y las prácticas urbanas que se dan en él.

Este articulo pretende mostrar el avance de la investigación desarrollada en el marco de la Maestría en Planeación Urbana y Regional de la Pontificia Universidad Javeriana. Por tal motivo, está subdivida en tres partes. La primera en donde se desarrolla el planteamiento del problema y las inquietudes de investigación, el segundo, en donde se desarrolla los fundamentos teóricos sobre los cuales se enmarco la investigación y, por último, se realiza un comentario acerca de la pertinencia de los fundamentos teóricos para la aplicación en el caso de estudio y la metodología propuesta. Se concluye realizando unas reflexiones finales acerca de la pertinencia de la investigación y sobre posibles aplicaciones en otros contextos.

\section{EL PLANTEAMIENTO DE LA INVESTIGACIÓN}

El espacio público puede considerarse cómo el eje estructurante de la ciudad, donde se permiten los encuentros y de anonimato, donde se realiza la cohesión social y los intercambios. Como lo menciona Jordi Borja, "la ciudad es el espacio público" (2003:119) el lugar de flujos y lugares, por tanto, este espacio se convierte en el lugar en donde se hacen visibles los cambios en las sociedades y en donde se puede dar la intervención urbana e incluso política en las ciudades (Sendra, Carrascal \& García, 2012).

Del estudio del espacio público no solo se han ocupado disciplinas como la arquitectura y el urbanismo, cada vez más, diversas disciplinas como la sociología, la ciencia política o la economía están interesadas en aportar a este campo de estudio. De esta forma, no existe una única definición de lo que representa el espacio público en la ciudad, puesto siempre depende de los ojos quien la mira. En esta investigación, se apostó por promover una definición holística, entendiendo este espacio desde la variedad de elementos que lo componen y la multivariedad de situaciones que ocurren en él.

A pesar de esto, al espacio público se le han otorgado una serie de características estáticas. Se habla de un lugar que permite la interacción entre personas, es decir "relacional", en donde los intereses de los transeúntes se conjugan de una forma perfecta, cada uno va, viene y no irrumpe su trayecto por la presencia del otro. El 
anonimato es entonces otra característica primordial, que se reafirma en la medida que existe un "otro" al que no conozco pero que identifico y respeto. Sin embargo, esta visión del espacio público puede llegar un ser un poco romántica cuando se trata de visualizar la realidad en las ciudades latinoamericanas.

Desde la planeación, se ha visto el espacio público como, un producto restante a la implantación edificatoria y actuaciones desligadas que desde el diseño urbano se realizan a elementos primordiales como "parques" y "plazas". En 1998, José María Ezquiaga en su texto sobre las reflexiones a la crisis del planeamiento urbano expuso "la necesidad de armonizar las técnicas urbanísticas con la complejidad e indeterminación de la realidad urbana y territorial" (3), manifestando la incapacidad del planeamiento urbano de dar cuenta de esa situación.

En esta línea, se encontró una diferencia sustancial entre la forma en que se produce el espacio público desde la mirada de la planeación, y la apropiación y resignificación que da la ciudadanía a estos espacios. Ciertamente, en cada espacio confluyen una serie de actos sociales, económicos, físicos y culturales, en intensidades y temporalidades distintas. Surgen entonces, este tipo de preguntas: ¿Cómo se abordado la planificación del espacio público en Bogotá? ¿Cuál es el imaginario del espacio público de los planificadores? ¿Existen varios espacios públicos? ¿Qué elementos permiten entender las dinámicas sociales y prácticas urbanas que se dan en los espacios públicos?

Por tanto, esta investigación está interesada no solo en entender cómo se ha abordado la planificación del espacio público, sino también entender cuál ha sido el papel de la planificación al tratar de abordar la dinámica de estos espacios de una forma más holística y compleja. Adicionalmente, se aboga en esta investigación por la comprensión profunda de las dinámicas sociales que ocurren en los territorios, a partir de la cual se puede llegar a comparar cómo las actuaciones en el espacio público tienen a homogenizar y a desconocer las relaciones sociales que se entretejen en la ciudad. De esta forma, la pregunta principal de esta investigación se refiere a ¿qué aporte se puede generar a la planeación urbana desde una reflexión sobre las prácticas urbanas que ocurren en el espacio público en Bogotá?

Realizar una mirada holística a las diferentes formas de espacio público, supone adentrarse en formas y razones en las que se hace uso de estos espacios, que elementos permiten que estas dinámicas ocurran y que normas formales y no formales las estimulan.

Existen tres razones principales por la cual es importante pensar el espacio público y su planificación. La primera, es que el espacio público ha sido pensado de una forma fragmentada y relegada dentro del proceso de planificación. Este es producto de "lo sobrante" ante el resto de elementos estructurantes como lo son los edificios y los equipamientos (Salazar, 2003; Gómez, 2012). Segundo, se puede argumentar que el espacio público es donde tal vez se consolida la mayor parte de la esencia urbana. Y en línea con lo que plantea Jordi Borja (2003), la calidad de las ciudades que queremos está ligada al entendimiento de las dinámicas que allí ocurren y a la forma en cómo la planeación urbana logra articular sus actuaciones bajo el entendimiento de estas nociones. Tercero, en el espacio público es donde se hacen visibles los clamores de la ciudadanía, los conflictos, los intereses políticos y expresiones culturales. Por lo tanto, para la planificación es indispensable pensar en estos espacios, de una forma más holística y plural, permitiendo que las voces de cada uno de los espacios pervivan con las actuaciones que se realicen en el espacio público y dejando a un lado una visión única y estática.

Se planteó como objetivo general de esta investigación examinar los discursos que acompañan la configuración de los espacios públicos en Bogotá y su relación con la influencia que ejercen las prácticas urbanas sobre el territorio. Como objetivos específicos se plantea primero, proponer un marco teórico que permita articular elementos de los discursos de la planeación del espacio público y los elementos y variables de las prácticas urbanas en la ciudad. Segundo, analizar los discursos que han guiado la planificación del espacio público en Bogotá. Tercero, comparar comparar dos espacios públicos en la ciudad de Bogotá que permitan ejemplificar la relación entre su configuración a partir de los discursos de la planeación y de las practicas urbanas que ocurren en ellos. Se seleccionaron dos lugares de estudio: los barrios Contador y El Salitre. Se seleccionaron estos lugares porque su planteamiento de espacio público se fue configurando de forma opuesta desde la perspectiva de su planeación. La Calle 140 ubicada al interior de los barrios Cedritos y Contador se configuró desde la perspectiva de la movilidad y del acceso a los conjuntos cerrados que se comenzaron a ubicar en esta zona, el espacio público por lo tanto, no fue un predominante en la configuración urbana de este sector. En oposición a este barrio, encontramos el proyecto Ciudad Salitre el cual su configuración respondió un planteamiento 
urbanístico realizado desde 1988. Se busca realizar entonces una comparación de las dinámicas urbanas de dos lugares en la ciudad, que hayan sido configurados de formas distintas desde la planeación urbana.

Se concluirá que los espacios públicos en Bogotá han sido pensados desde unos criterios generales y estáticos, lo cual no han permitido que los cambios y transformaciones en su uso, sean percibidos como algo positivo y parte de la misma dinámica de la ciudad. Por el contrario, han frenado formas de apropiación desconociendo la realidad de como las comunidades y ciudadanos resignifican y se apropian de él. De esta forma, la planeación urbana debe comenzar a replantear la forma en que se piensan los espacios públicos desde características homogéneas, a mirar particularidades de los territorios. Permitiendo flexibilizar los instrumentos de actuación y sus políticas de gestión y cuidado del espacio público.

Para el desarrollo de esta investigación se plantea una metodología cualitativa, en la medida en que no incurre en el análisis de datos estadísticos, ni numéricos para su desarrollo, por el contrario, busca realizar relaciones e inferencias a partir de la información recopilada en las fuentes primarias y en el trabajo de campo. En palabras de Sampieri "los planteamientos cualitativos (..) resultan apropiados cuando el investigador se interesa por el significado de las experiencias y valores humanos, el punto de vista interno e individual de las personas y el ambiente natural en que ocurre el fenómeno estudiado" (2006: 550)

Esta investigación es de tipo exploratoria, ya que busca entender los principales discursos que han guiado la práctica de la planificación del espacio público, así como aportar nuevos elementos de discusión en esta práctica. Es evaluativa, en la medida que busca determinar cuáles han sido los principales aciertos y desaciertos en la planificación del espacio público. Es comparativa, en la medida que busca realizar un ejercicio de comparación a partir de la selección de dos casos de estudio que permitirán dilucidar la dinámica social, económica y política de los espacios públicos para realizar un comparativo con las actuaciones que allí se han realizado.

Dentro del análisis de los instrumentos de investigación, se utilizará como referente principal el sistema socioterritorial de Jerome Monnet (2013) para llegar a una aproximación sobre la acción en el territorio desde las políticas urbanas, las cuales se harán a partir de una revisión documental de fuentes primarias y secundarias de los documentos de política e implementación del espacio público, haciendo énfasis en la conformación de discursos alrededor del espacio público en Bogotá.

Para el segundo momento de análisis de casos, la metodología será mucho más abierta con el fin de realizar un diagnóstico de las zonas, a partir de revisión documental, entrevistas semi-estructuradas a habitantes de la zona, y observación participante. A pesar que ya se tiene una selección preliminar de estos lugares, es importante resaltar que se permitirá que la investigación vaya generando puntos de quiebre sobre los cuales se podrá pulir esta selección. Se buscará comenzar por su caracterízación, los criterios de planeación que los sostienen, y posteriormente las prácticas urbanas que contienen las formas de apropiación, significados de uso, normas formales e informales que rigen el actuar en el espacio urbano y similitudes entre ambos.

Esta investigación supone un trabajo de campo exhaustivo en las zonas seleccionadas, se pretende utilizar un periodo de dos meses en los cuales se podrá recopilar la información solicitada. Para el análisis de la información se tendrá que sistematizar la información recopilada a partir de entrevistas semi- estructuradas y cruzar con la información recopilada en el diario de campo como elemento fundamental de la observación participante. Posterior a este momento, se debe llevar a cabo una tarea de comparación crítica frente a lo encontrado en el primer momento de análisis documental de planeación y lo encontrado en el trabajo de campo.

\section{MARCO TEÓRICO}

Retomando la idea expuesta en la introducción, se entiende la ciudad como una realidad compleja y dinámica; en donde las actuaciones de los planificadores no han logrado dar cuenta de esta realidad (Ezquiaga, 1998) y los espacios públicos se encuentran inmersos en una dualidad: la planeación y la realidad social. El marco teórico de esta investigación, está estructurado a partir de la noción de espacio público, de la planeación urbana como como ordenador del proceso de formación de este espacio en la ciudad, y de las prácticas ciudadanas que suceden en ese espacio. Este capítulo se aborda, primero, una conceptualización del espacio público y sus componentes de análisis; segundo, una aproximación a la forma en la que la planeación urbana ha abordado el espacio público y, por último, las prácticas urbanas que se dan en él. Estos subcapítulos conforman la base 
conceptual para el desarrollo y entendimiento de la planeación de los espacios públicos en Bogotá y las prácticas urbanas que suceden en ellos.

\subsection{El espacio público como concepto plural y multidimensional}

Esta investigación gira entorno al espacio público, como lugar fundamental en la ciudad. Por tanto, inicia por realizar un abordaje a la construcción del espacio público como concepto, haciendo énfasis en una mirada plural y multifuncional.

Como se mencionó al inicio, diferentes disciplinas han abordado el espacio público desde diversas perspectivas, ya que no solo llama su atención de disciplinas como la arquitectura y el urbanismo, sino también a disciplinas de las ciencias sociales como la sociología y la antropología. Esta sección tiene como objetivo dar cuenta de las diferentes nociones que se encuentran en la literatura sobre el espacio público. Estas abordan una mirada política, una mirada desde la conflictividad, una mirada opuesta desde la posibilidad de cohesión social que permite la vida social en los espacios públicos, y, por último, una mirada activa al ejercicio de ciudadanía a través de la participación.

Se parte aquí, de la visión que planteada por Jordi Borja (La Ciudad Conquistada, 2003) donde argumenta que "en el espacio púbico se realiza la síntesis de lugares y flujos. Y la ciudad es el espacio público, lugar de la cohesión social y de los intercambios" (p. 119) (cursivas de la autora). Por lo tanto, el espacio público se convierte en el eje estructurante en la ciudad. En línea con lo que plantea Borja, el entendimiento del espacio público no puede estar desligado de los conceptos de ciudad y ciudadanía, plantea que existe una relación dialéctica entre los tres, argumentando que la calidad de espacios públicos que se crean, dependerá en gran medida la calidad de vida de la ciudad, y reconoce abiertamente el rol de los ciudadanos como habitantes de este complejo urbano.

Sin embargo, si el espacio público está ligado necesariamente a la ciudad, y la ciudad al espacio público, ¿Cuáles serían los componentes de análisis para entender este espacio? Se argumenta aquí que los componentes para realizar el análisis del espacio público deben partir del entendimiento de su vinculación con diferentes dimensiones como lo físico, lo político, la conflictividad, la cohesión social y la participación. Estas dimensiones agrupan siempre la idea de un espacio físico y unos elementos intangibles que son producto de la interacción socio-colectivo en la ciudad (Del Castillo, 2003, p. 49). De ahí que Fabio Zambrano (2003) haga referencia a la polisemia del espacio público refiriéndose a la posibilidad que tiene el espacio público por contener diferentes significados.

La dimensión física, tiende a ser la más evidente cuando se habla de espacio público, precisamente porque tiene una espacialidad definida, es un lugar, un punto definido y tangible. En oposición a los espacios privados, los espacios públicos conforman esa trama urbana que va desde calles, plazas, parques y andenes, los cuales agrupan el conjunto de lugares de encuentro y monumentos. Para Jordi Borja y Zaida Muxi, la dimensión espacial del espacio público no se puede desligar de la conformación de la ciudad (2000, p. 41) .

Sin embargo, la dimensión física no es la única que permite entender la conformación de los espacios públicos, sino es a través de los cuales se conjuga y se recrea la vida de los ciudadanos, espacio que se convierte en el factor determinante para su teorización.

La noción del espacio público como lugar político, parece ser constante en la revisión bibliográfica (Hernandez, 2003; Alguacil, 2008), en donde el espacio público representa el lugar para la democracia, la participación y el clamor de la ciudadanía para ejercer sus derechos. Para Fabio Zambrano (2003), por ejemplo, representa un espacio de encuentro político y la posibilidad de expresar las injusticias de la sociedad. Dentro de su argumento, muestra al espacio público como elemento fundamental de la democracia participativa, en donde podrá verse reflejado el reto que tiene la ciudad latinoamericana en la actualidad en torno a diferentes temas. Para Julio Alguacil (2008) en cambio, plantea la posibilidad del espacio público como lugar para la acción política en respuesta a la necesidad de repensar la ciudad desbordada por los resultados de los procesos de globalización y capitalismo. Aunque para Alguacíl el espacio público es el lugar de la circulación, el hacer y el estar (p. 204), también lo asocia a un espacio colectivo en la medida que existe interacción entre distintos actores, generando así un inevitable conflicto. 
En esta misma línea, Carlos Mario Yori (2011) muestra este espacio como un "lugar de conflicto" (p. 13) en donde se encuentran choques entre actores, usos y formas de apropiación. El conflicto es entonces inherente en este espacio. De esta forma, el autor plantea que existe una ausencia clara en la incorporación de políticas públicas en materia de derechos ciudadanos que permitan generar una mirada positiva sobre la estructuración y gestión de proyectos en el espacio público.

La idea de la cohesión territorial del espacio público es planteada por Adrián Vergara et al. (2015), quien concibe este espacio como un "enfoque funcional, que permite el desarrollo de políticas concretas que promuevan el desarrollo integrado de los territorios, que impulsen políticas locales y de coordinación intersectorial" (p. 2). De esta forma, la cohesión territorial es una característica que subyace de la conformación del espacio público y que permitirá entender en el territorio, no solo como unidad sino como una globalidad articulada por medio de las políticas urbanas.

Por último, el espacio público y su planificación demanda la participación ciudadana y el involucramiento de los actores que realizan su uso, tal como lo plantea Raquel Perahia (2007). Según la autora, su argumento a favor de la cooperación de los ciudadanos permitiría la diversidad de soluciones y la mejora de la calidad ambiental en su conjunto. Además, llama la atención sobre la tarea interdisciplinaria a la que se enfrentan los planificadores a la hora de planear el espacio público.

La conceptualización del espacio público plantea interrogantes pertinentes para entender la vida sociedad y retos para la planeación urbana, en la medida en que representa un lugar complejo, multifuncional y diverso que requiere de diferentes dimensiones para poder ser comprendido.

\subsection{Los discursos del espacio público para la planeación urbana}

A partir del reconocimiento de la pluralidad en las dimensiones y enfoques que el espacio público puede generar, es pertinente realizar una reflexión desde la práctica de la planificación. La planificación se puede definir como "ese proceso de descripción, análisis y evaluación de las condiciones de funcionamiento de las ciudades para poder generar propuestas de diseño y formular proyectos que permitan regular la dinámica urbana y ambiental de toda la ciudad (...) y atender las anomalías existentes entre sus condiciones del desarrollo económico, social y espacial" (Ornes, 2009: 202). Por tanto, para la planificación urbana, el espacio público ha tenido una connotación que ha influido en la forma en que se han propuesto soluciones, programas y proyectos para las ciudades.

Algunos autores argumentan que el espacio público es una noción puramente moderna, sin embargo, para otros, el espacio público siempre ha existido en las ciudades. Desde el medioevo, existían esos lugares de tránsito entre edificios y entre lugares de actividades. María Fabiola Pardo argumenta que los primeros espacios públicos dedicados exclusivamente a la integración de algunas clases sociales nacieron en Europa, más específicamente en Francia durante el siglo XVII. Aunque estos no eran necesariamente abiertos a todas las clases sociales, si representaban lugares de intercambio de mercancía. Con la llegada de la revolución industrial, y su caos, comienzan a existir los primeros intentos por pensar el espacio público. El ejemplo más contundente es la renovación de París realizada por Georges-Eugène Haussmann, quien transformó la calle, y los bulevares. Según Gamboa, permitió que el espacio público se convirtiera en un espacio democrático para el caminar de todos los habitantes. "Sus amplias aceras arborizadas, el alumbrado público y el amoblamiento urbano conforman un nuevo espacio, accesible a todo el mundo y democrático, abriendo la totalidad de la ciudad, por primera vez en su historia, a todos sus habitantes" (2003, p. 14). La construcción de los bulevares buscaba organizar y mejorar la ciudad, la cual era considerada como un lugar inhospito, congestionado, y de alguna manera indeseable.

Soportados en las utopías del siglo XIX, y los intentos aún insípidos de transformar la realidad urbana que se relacionaba al hacinamiento de la ciudad industrial y su desorden, los arquitectos y urbanistas, pertenecientes al Movimiento Moderno, plantearon un modelo completamente diferente sobre la estructuración de la ciudad y, por lo tanto, el rol del espacio público. Forjando ideas sobre "el futuro de las ciudades", la visión funcionalista, propendió a dar predominancia a la circulación del automovil que a la del peatón y carruajes. Según Gamboa, la ciudad funcional no se recorre, ni se vive, sino se atraviesa. No se recorre porque dejan de existir los lugares de encuentro y de intercambio, y, por lo tanto, pierden según Gamboa el sentido social. Se atraviesa entonces a partir de una red de vías y parques desarticulados que el mismo habitante que la recorre no la conoce. La ciudad es entendida como "un lugar de producción, como una gran fábrica moderna" (p. 16). 
Esta forma de pensar la ciudad y los espacios públicos fue altamente criticada por varios autores, entre ellos Jane Jacobs (1973) y James Holston (2008), anunciando así la muerte de los espacios públicos. Incluso autores latinoamericanos como Angela Giglia (2002) y Emilio Duhau (2009) han puesto de manifiesto la crisis del espacio público, en donde se evidencia la "imposibilidad de vivir juntos en las grandes ciudades y la disolución de los urbano como lugar de encuentro y de intercambio" (Duhau, 2009, p. 213) (cursivas de la autora). Estos cuestionamientos llevaron desde los años 70 s a comenzar a pensar la ciudad desde otra perspectiva y más aún con el producto que dejaba la intervención bajo el paradigma del Modernismo. La planeación urbana comienza a realizar estudios más cautelosos sobre la forma urbana, entendiendo que el espacio públic s producto de la unión entre equipamientos privados y públicos, edificaciones, plazas, parques y monumentos históricos.

La ciudad contemporánea ha comenzado a entender los espacios públicos en las ciudades de formas diferentes, basados no solo en la conformación a partir de sucesos históricos, sino en unión con las influencias del movimiento funcionalista. En la búsqueda de pensar el espacio público de forma completa y holística, varios planificadores han tratado de hacer una diferenciación entre las dinámicas sociales que suceden en lo público, de las que suceden en lo privado. Bajo esta perspectiva se encuentran Núria Ricart y Antoni Remesar (2013) quienes entienden la idea de espacio público "como el articulador de acontecimientos que intervienen en la vida de las ciudades (...) entendido como una red poliédrica y multidimensional" (2013, p. 5). Bajo este entendido argumentan que el análisis de este espacio en la ciudad debe abarcar por diferentes dimensiones como lo son: el límite entre el espacio público y la esfera pública, el espacio público construido y su conformación, su mirada desde la contemporaneidad, su dimensión social y finalmente la perspectiva de su gestión en las ciudades.

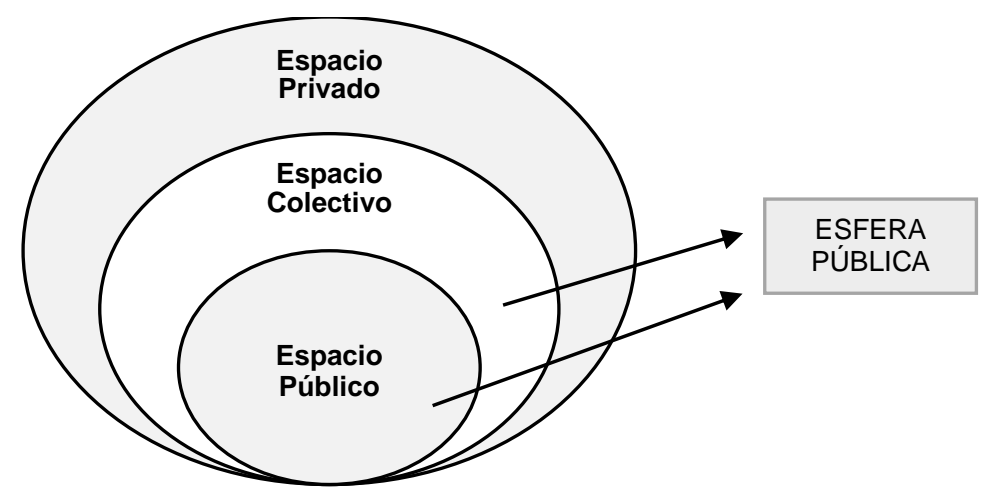

Grafico 1. Relación entre lo público, lo colectivo y lo privado Elaboración propia con base en Ricart \& Remesar (2013: 9).

Ricart y Remesar (2013) plantean una separación necesaria entre espacio público y el espacio colectivo (grafico 1). El espacio colectivo según Manuel Cerasi (1990) "puede ser definido como el sistema unitario de espacios y edificios en el territorio urbanizado que tienen una incidencia sobre la vida colectiva, que definen un uso común para amplios estratos de la población y que constituyen la sede y los lugares de su experiencia colectiva" ( $p$. 87). De esta forma, argumentan que el espacio colectivo contiene al espacio público, pero que no todo el espacio colectivo hace parte del espacio público. El espacio público estaría definido por su "dominio público", mientras que el resto del espacio colectivo sería de dominio privado. Es pertinente realizar esta separación precisamente para lograr entender que el espacio colectivo traspasa la frontera del espacio público definido legalmente. Existe un límite casi imperceptible. Se puede argumentar que es necesario entender las nuevas configuraciones a las que se somete el espacio público en la ciudad. El espacio público finalmente es un espacio colectivo y de experiencia comunal, y de ahí que Cerasi (1990) argumente que "en la ciudad occidental la vida colectiva se completa en gran parte fuera del suelo público" (p. 90). 


\subsection{Las prácticas urbanas en los espacios públicos}

La forma en que se vive y se apropian los espacios públicos, sus usos y significados se convierte en un elemento fundamental para esta investigación. La planeación urbana debe, por lo tanto, buscar entender la forma en que estos elementos se relacionan y como se reproducen imaginarios y usos cotidianos en estos espacios. De ahí que se argumente la necesidad de entender las prácticas urbanas desde la forma en que se apropian los espacios y la forma en que se generan significados.

A partir del trabajo realizado por Michel de Certeau (2000) acerca de las prácticas cotidianas, se buscará primero determinar algunas categorías de análisis propuestas por el autor para generar una discusión acerca de lo que se entiende por "practicas urbanas". Las trayectorias, las estrategias y las tácticas son algunos de los elementos que se abordaran. Posteriormente, se propondrán las variables de análisis para entender y estudiar las prácticas urbanas en el espacio público. Se argumenta aquí que el estudio del espacio público no puede desprenderse del estudio de las prácticas urbanas que ocurren en él. Como se mencionó anteriormente el espacio público es un producto social y no es un concepto estático ni dado por sí mismo, tiene un carácter plural y multidimensional.

En el trabajo realizado por Michel de Certeau (2000) se dedica principalmente a realizar una reflexión sobre las practicas cotidianas y culturales. El autor escribió el libro La invención de lo cotidiano l: Artes de hacer haciendo énfasis en "el rechazo a la uniformidad que un poder administrativo querría hacer imperar en nombre de un conocimiento superior y del interés común" (De Certeau, 2000, p. XVIII). Por lo tanto, este libro hace un llamado al conocimiento que se produce en lo cotidiano y en la vida de cada sujeto en la sociedad.

Para esta investigación se tomarán como base fundamental tres conceptos que según de Certeau deberían entenderse dentro de las prácticas cotidianas o 'maneras de hacer'. Por práctica cotidiana, de Certeau se refiere a los modos de operación y acción que realizan no solo los individuos sino un colectivo de individuos y las formas en que estas operaciones se relacionan con otras. Las prácticas, que son consideradas por de Certeau como creativas, por su naturaleza irreverente al sistema, tienen sus propias lógicas, es decir que no necesariamente existe alguien que las inventa, sino que inconscientemente surgen, pero a ellas se les puede encontrar una organización y una lógica oculta que las guía. Las prácticas cotidianas son sustituidas por la huella, ya que ellas enmarcadas en un tiempo y espacios definen un acontecimiento que es y deja de ser para convertirse en algo que sucedió.

Los tres elementos clave para entender las prácticas en lo cotidiano se refieren a: trayectoria, estrategia y táctica. La trayectoria, corresponde a un movimiento sobre un plano, y es temporalmente irreversible. La estrategia, corresponden a los cálculos voluntarios de los sujetos, que requiere una visión lejana del 'ambiente' para poder definir la acción. En ellas, un lugar puede convertirse en un lugar propio y luego dejar de serlo, todo depende del manejo que le dé él agente, es otras palabras es un modelo estratégico de los espacios. Por último, la táctica que corresponde a "un cálculo que no puede contar con un lugar propio, ni por tanto con una frontera que distinga al otro como una totalidad visible" (De Certeau, 2000, p. L). La táctica siempre es'ta sujeta al tiempo, juego con los acontecimientos fortuitos y los vuelve acciones, es entonces el "acto y manera de aprovechar la ocasión" (De Certeau, 2000, p. L). A diferencia de la estrategia, la táctica carece de poder, lo que hace que la estrategia sea el campo de la racionalidad política y económica en donde prima la voluntad y el poder de la realización de una acción.

De Certeau localiza el campo de las prácticas urbanas desde abajo en donde viven como practicantes y aparece "como forma elemental de esta experiencia, (los) caminantes, Wandersmänner, cuyo cuerpo obedece a los trazos gruesos y a los más finos de un 'texto' urbano que escriben sin poder leerlo" (2000, p. 105). El caminar, es entonces para de Certeau no solo un proceso de apropiación de espacio urbano, sino la realización misma del lugar. Es el caminante entonces quien realiza práctica el espacio, que según con conjunto de posibilidades y prohibiciones reacciona y actualiza su actuar en él (2000, p. 110). Manuel Delgado (2002) está de acuerdo con esta noción cuando argumenta que "el usuario del espacio urbano es casi siempre un transeúnte, alguien que no está allí sino de paso” (p. 93).

Aunque Michel de Certeau (La invención de lo cotidiano I. Artes de hacer, 2000) relaciona necesariamente las tácticas, estrategias y trayectorias sumergidas en el espacio tiempo, Soto (Repensar las prácticas espaciales: rupturas y continuidades en la experiencia cotidiana, 2013) soportada en los planteamientos de Manuel Delgado (2007) y Erving Goffman (1989) hace especial énfasis en las prácticas urbanas como "territorializaciones 
fugaces", argumentando que "prácticas urbanas (..) construyen una sociabilidad urbana 'dispersa' (Delgado, 2007), la espacialidad aparece aquí en términos multiescalares, procesales y variables complejos" (2013, p. 4). La ciudad y lo urbano están compuestos necesariamente por prácticas urbanas, practicadas por los individuos, las cuales como se mencionó anteriormente componen son solo el paso inicial para la huella en el territorio, sino que se pueden descomponer en estrategias, tácticas y trayectorias.

\subsection{Propuesta de análisis para el estudio del espacio público y su planeación}

Se propone en esta investigación un esquema de análisis para entender los discursos que han guiado la planificación del espacio público y su relación con las prácticas urbanas. Este esquema de análisis se basa en dos conceptos fundamentales desarrollados por Henri Lefebvre $(1974,1994)$ y Jerome Monnet $(2013)$ ambos autores provenientes de la geografía, aportan el entendimiento de la producción del espacio.

El espacio público es un producto social como se mencionó anteriormente, está compuesto por una dimensión física, y unas dimensiones intangibles que permiten que en él se desarrollen el actuar de la ciudadanía. Por tanto, es pertinente para la planeación esta aproximación teórica en la medida que permite entender cómo son los flujos entre un espacio planeado y un espacio actuado y vivido. Autores como Henri Lefebvre, David Harvey y Edward Soja, quienes han estudiado la producción del espacio en las ciudades argumentan que el espacio permite un sin número de interacciones, también asociados a unas lógicas de producción.

Henri Lefebvre (2014), por ejemplo propone una triada para entender la lógica de la espacialidad. Por un lado, tenemos la práctica espacial que se relaciona "con el espacio percibido, el más cercano a la vida cotidiana y a los usos más prosaicos, los lugares y conjuntos espaciales propios de cada formación social, escenario en que cada ser humano desarrolla sus competencias como ser social que se sitúa en un determinado tiempo y lugar" (Delgado, 2013, p. 2). Es además es el que recibe los usos por parte de los habitantes, e implica por tanto un grado de performance y cohesión en las dinámicas que allí ocurren. Son estas prácticas las que hacen que el espacio sea un producto social. Por otro lado, tenemos el espacio vivido, que son los espacios ya practicados pero imbuidos en sistemas simbólicos complejos que abarcan imágenes e imaginarios, de esta forma Lefebvre los denomina espacios de representación. Por último, tenemos los espacios concebidos, o la representación del espacio, que es aquel espacio provisto por conocimientos técnicos que le permite actuar sobre él. Es el espacio de dominación, de los urbanistas, planificadores y arquitectos que a través de ideologías influyen en la construcción del espacio.

Por otro lado, está el sistema socio-territorial propuesto por Jerome Monnet compuesto a partir de una interdeterminación entre territorio, territorialidad y territorialización. Este sistema hace referencia a las interacciones que existen entre la sociedad y su entorno físico, explicando que "el territorio corresponde a un espacio definido, producido y ordenado por acciones humanas, mientras la territorialidad representa la dimensión espacial de los actores y los valores que estos le atribuyen al espacio intervenido. En cuanto a la territorialización, está cubre el conjunto de acciones implementadas por estos actores en nombre de sus valores" (2013, p. 1). En otras palabras, el territorio es el lugar físico donde sucede la acción humana, la territorialidad son los valores otorgados a ese territorio y lo que el autor denomina "sentido de pertenencia" (p. 4) y, por último, la territorialización entendida como la definición de acciones basados en un sistema de valor que se utilizan para modificar el territorio. En el Grafico 2 se puede observar dos bucles de relación entre los conceptos. 


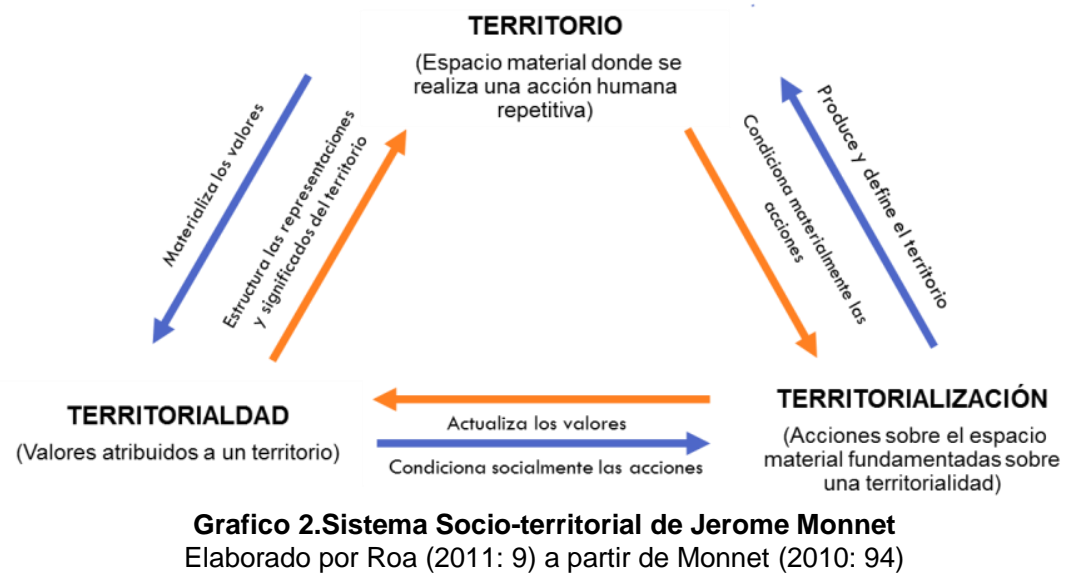

Se argumenta que los dos conceptos son comparables y vinculantes para el análisis que se propone en esta investigación. El territorio según Monnet es el espacio donde se da la acción, en el caso de Lefebvre es el espacio percibido en donde se dan los usos y las acciones humanas. El espacio vivido, se puede relacionar con la territorialidad en la medida que conforman ese complejo de significados y valores que se le atribuyen al territorio una vez es percibido, actuado y vivido. Y, por último, el espacio concebido se puede relacionar con lo que Monnet denomina la territorialización en la medida son esas acciones y que se pueden dar en el territorio. Aunque para Lefebvre es el espacio de poder, otorgado en este caso al rol de los planificadores y urbanistas, para Monnet las acciones no provienen necesariamente de un tipo de actores sino en general de cualquier acción humana. Mientras que Lefebvre explica como las acciones pueden provenir de relaciones de poder, Monnet explica cómo las acciones afectan lo que sucede en el territorio y a la vez su influencia en el tipo de acciones que se dan.

Dentro de la apuesta teórica que se plantea en esta investigación, el análisis del espacio público puede verse enmarcada por estos dos conceptos. El espacio público es a su vez un territorio, es decir un lugar físico, sobre el que suceden acciones de parte de la ciudadanía y de los planificadores. De esta forma, no se pueden desligar los espacios percibidos de los vividos, ni las acciones de lo que sucede en el territorio. Esta será la hipótesis de la que se parte en esta investigación y que permitirá realizar el análisis entre los discursos que han guiado la planeación del espacio público y las prácticas urbanas que ocurren en ellos.

\section{PERSPECTIVAS DE ANÁLISIS}

A partir de la revisión bibliográfica y teórica realizada anteriormente, se plantea para esta investigación el desarrollo de dos objetivos específicos que tienen que ver con el estudio sobre el discurso de las bases y premisas que han guiado la planificación del espacio público en Bogotá, por un lado, y por el otro, realizar un diagnóstico de las prácticas urbanas y dinámicas internas de dos lugares particulares para dilucidar y dialogar sobre las representaciones simbólicas, tipos de uso, características generales y las percepciones que conviven en estos contextos. A continuación, se pretende mostrar cómo las bases teóricas permitirían enriquecer estos dos puntos específicos de la investigación.

Si bien, hasta hace poco la planeación urbana ha comenzado a entender la multiplicidad de elementos que suceden en el espacio público, es pertinente entonces comenzar a indagar a partir de los instrumentos de ordenamiento territorial en Bogotá y sus distintas políticas la forma en que se pensado el espacio público en Bogotá. Dentro de los distintos instrumentos, se pueden mencionar los más relevantes, la Política Nacional de Espacio Público contenida en el CONPES 3718 de 2012, y a nivel distrital están el Plan de Ordenamiento Territorial en Bogotá - POT (Decreto 190 de 2004), el Plan Maestro de Espacio Público de Bogotá - PMEP (Decreto 215 de 2005) entre otros.

De esta forma, se busca que a partir del sistema socio-territorial de Monnet (2013) y la visión del espacio "concebido" planteado por Lefebvre (2014) se pueda dilucidar cómo estas acciones de política e instrumentos de planificación se territorializan en el espacio urbano, mostrando puntos de quiebre y fragmentos en la 
actuación urbanística. A partir de este análisis, será pertinente preguntarse acerca del espacio público que se está construyendo la ciudad y la forma en que este está afectando a la conformación de la ciudad.

Por otro lado, el análisis de los casos pretende ser un pretexto para dilucidar cómo los espacios públicos pueden contener distintas características, así como elementos similares. Por lo tanto, esta investigación no está enfocada en ser un caso de estudio sobre los lugares seleccionados, pero si una ejemplificación de la forma en que el espacio es vivido, percibido y en donde se pueden resaltar prácticas urbanas interesantes que el planeador debe aprender a identificar a partir de esa mirada cautelosa.

Se han seleccionado dos lugares, el primero se encuentra ubicado en los barrios Cedritos y Contador, ubicado en la Localidad de Usaqúen el cual cuenta con un corredor comercial muy importante que se ubica sobre la Calle 140 entre Avenida 19 y Avenida 9. Este corredor se ha ido conformado paulatinamente alrededor de diferentes conjuntos residenciales cerrados, sin embargo la actividad peatonal, asociada a la actividad comercial y residencial ha permitido la conformación de un corredor activo en terminos de prácticas culturales. Desde la planeación no fue concebido como un espacio público desde las premisas que guían la planeación de estos espacios públicos en la ciudad. El segundo, se refiere al proyecto urbano Ciudad Salitre ubicado entre la calle 26 al norte, la Av. Carrera 50 al oriente, el Canal San Francisco al sur y la Av. Carrera 70 al occidente. Desde la perpectiva de la planeación fue una apuesta de gestión urbana que comenzó a realizarse desde 1988. La avenida La Esperanza representa no solo un conector vial importante, pero la actividad colectiva y pública no se da en grandes proporciones en el espacio público. Estos son algunos de los interrogantes e hipótesis que se plantean cuestionar al desarrollar la investigación.

Para el análisis de estos espacios no solo se partirá del análisis de la triada de Lefebvre (2014) desde el espacio percibido y vivido, sino también apartir de la identificación de estrategias, tácticas, y trayectorias que pemiten entender las prácticas cotidianas en estos espacios. Se proponen nueve variables que son necesarias para el estudio de las prácticas urbanas: formas de interacción y lugares de encuentro, tránsitos y movilidades, lugares de permanencia y apropiación, temporalidad, multiculturalidad, codificación de imágenes e imaginarios, indentidad y memoria y escala.

\section{CONCLUSION Y REFLEXIONES FINALES}

Es así como a partir del interés por realizar una mirada crítica a la práctica de la planeación del espacio público, se ve imbuido en el gran campo de las relaciones humanas, comerciales y de flujos a las que la ciudad está simultáneamente inmersa. Esta investigación llama la atención acerca de la necesidad permanente de vincular las particularidades de los territorios, de las personas y habitantes, así como de permitir que distintas voces permanezcan en la reflexión constante acerca de la ciudad.

A partir de la reflexión de las bases teóricas, se puede dilucidar que la planeación urbana ha comenzado a ver lo físico espacial, dentro de un tejido urbano complejo en donde lo invisible reina. Y, por lo tanto, ya han existido acercamientos desde la teoría a complejizar la mirada al espacio público. Bogotá por su parte, es una realidad lejana, a partir del análisis de los instrumentos de planificación y de los dos casos particulares, se pretende ejemplificar como la planeación urbana hacia el espacio público ha estado enfocada principalmente en su recuperación hacia unos usos preestablecidos, en donde la apropiación y la pervivencia de las prácticas urbanas realizadas por los ciudadanos se encuentran en un plano distinto para su actuar.

La planeación urbana enfrenta retos importantes y pertinentes, ya que las ciudades son sistemas complejos. De esta forma, esta tesis busca aportar a este campo de estudio, buscando la inclusión de la importancia de las prácticas urbanas en la planeación y planificación. Esta investigación pretende, además, plantear criterios que permitan pensar y planear el espacio público en contexto similares como Latinoamérica. La forma que toman las prácticas urbanas está directamente relacionada con las características particulares de la ciudad y de los habitantes, sus costumbres y particularidades. Por lo tanto, es posible que a través del estudio de un caso particular como Bogotá, se puedan vislumbrar formas y metodologías de entender lo público en la ciudad. 


\section{BIBLIOGRAFÍA}

ALGUACIL, J. (2008). "Espacio público y espacio político. La ciudad como el lugar para las estrategias de participación”. En Polis. Revista de Universidad Bolivariana, v.7 n²0; pp 199-223.

BORJA, J. (1998). Ciudadanía y Espacio público. En: Ciutat real, ciutad ideal. Significat i funció a l'espai urbá modern. Urbanistats (7). Barcelona: Centro de Cultura Contemporánea.

BORJA, J. (2003). La Ciudad Conquistada. Madrid: Alianza Editorial S.A

BORJA, J \& MUXI, Z (2003). El espacio público, ciudad y ciudadanía. Barcelona: Electa.

CERASI, M. (1990). El espacio colectivo de la ciudad: construcción y disolución del sistema público en la arquitectura de la ciudad moderna. Barcelona: Oikos-Tau.

DE CERTEAU, M. (2000). La invención de lo cotidiano I. Artes de hacer. México D.F: Instituto Tecnológico y de Estudios Superiores de Occidente.

DAZA, J. (2008). Espacio público y calidad de vida urbana. La intervención en el espacio público como estrategia para el mejoramiento de la calidad de vida urbana. [tesis de maestría], Bogotá, Pontificia Universidad Javeriana, Maestría en Planeación Urbana y Regional.

DEL CASTILLO, J. (2003). "El urbanismo público" En: Bogotá y lo público: construcción de lo público. Bogotá: Universidad de los Andes (pp. 47-58)

DELGADO, M. (2002). Etnografía del espacio público. Revista de antropología experimental, (2):91-97.

DUHAU, E. (2009). Vida y Muerte del Espacio Público 1. En: Rodríguez, M. A. y Roze, J. P. (comps.), Ciudades Latinoamericanas IV: Políticas, acciones, memoria y reconfiguración del espacio urbano. México, Asociación Latinoamericana de Sociología, pp. 213-238.

DUAHU, E \& GIGLIA, A (2008). Las reglas del desorden: habitar la metrópoli. México: Siglo XXI Editores, Universidad Autónoma Metropolitana, Unidad Azcapotzalco.

EZQUIAGA, JOSÉ MARÍA (1998) ¿Cambio de estilo o cambio de paradigma? Reflexiones sobre la crisis del planeamiento urbano. En Urban 2:(3 - 36).

GAMBOA, P. (2003). El sentido urbano del espacio público. Revista Bitácora, 7(1):13-18.

GIGLIA, A. (2002, diciembre). Privatización del espacio, auto segregación y participación ciudadana en la ciudad de México: el caso de las calles cerradas en la zona de Coapa (Tlalpan, Distrito Federal). Revista del Centro de Estudios Mexicanos y Centro Americanos, p. 1-21.

GÓMEZ, V. (2005). "Introducción". En: Murillo, G \& Gómez, V. (comps). Redefinición del espacio público: eslabonamiento conceptual y seguimiento de las políticas públicas en Colombia. Bogotá: Facultad de Ciencias Sociales, Universidad de los Andes.

HARVEY, D. (2004). Spacetime and the world. En Gieseking, J \&Mangold, W (Eds.) The People, Place, and Space Reader. (pp. 12-16) New York: Routledge.

HERNÁNDEZ, A. (2003), "Ciudadanía y espacio público: participación o segregación" en ALGUACIL, J. (ed.) Ciudadanía, ciudadanos y democracia participativa, Fundación César Manrique, Teguise, Lanzarote, pp. 15-39.

HOLSTON, J. (2008 julio-diciembre). La Muerte de la Calle. En: Antípoda: Revista de Antropología y Arqueología. Bogotá: Universidad de Los Andes (pp. 258 - 292).

JACOBS, J. (1973). Muerte y vida de las grandes ciudades. Madrid: Península.

LEFEBVRE, H. (2014). The production of space. En Gieseking, J \& Mangold, W (Eds.) The People, Place, and Space Reader. (pp. 289-293) New York: Routledge. 
MONNET, J. (2013). El territorio reticular. En Cruz B.N (coord.) Enfoques y métodos en estudios territoriales. (pp. 137-167) Manizales: Universidad de Caldas. (Traducción por A.F. Cardona Jiménez de un artículo originalmente publicado en francés en: Anthropos n²27, p.91-104, Barcelona, 2010).

MONNET, J. (2016, 28 de abril). "Territorialidad, territorialización, territorio: del Estado a los ciudadanos, aproximación post-colonial y post-funcionalista" [conferencia] Grupo de Políticas Públicas- Maestría en Planeación Urbana y Regional. Pontificia Universidad Javeriana, Bogotá.

MURILLO, G. \& MÁRQUEZ, T (2005). "La redefinición del espacio púbico en Bogotá: eslabonamiento conceptual y seguimiento de las políticas públicas en la última década". En: Murillo, G \& Gómez, V. (comps). Redefinición del espacio público: eslabonamiento conceptual y seguimiento de las políticas públicas en Colombia. Bogotá: Facultad de Ciencias Sociales, Universidad de los Andes.

ÓRNES, S. (2009). El urbanismo, la planificación urbana y el ordenamiento territorial desde la perspectiva del derecho urbanístico venezolano. En Revista Politeia, Instituto de Estudios Políticos № 42(32)197-225.

PARDO, M. (2008). Territorialidades cívicas: espacio público y cultura urbana en Bogotá. Bogotá: Universidad del Externado.

PERAHIA, R. (2007, 1 de junio). "Las ciudades y su espacio público" [conferencia], IX Coloquio Internacional de Geocrítica: Los problemas del mundo actual soluciones y alternativas desde la geografía y las ciencias sociales. Universidad Federal do Rio Grande do Sul. Porto Alegre, Brasil.

RICART, N \& REMESAR, A. (2013). “Reflexiones sobre el espacio público”. On the W@terfront. № 25 (pp. 5 35). [online] Recuperado en: http://www.raco.cat/index.php/Waterfront/issue/view/19804/showToc

ROJAS TRIANA, A. (2011). Ciudad y políticas públicas de espacio público: Algunas reflexiones sobre la interdeterminación entre territorio, territorialidad y territorialización desde el espacio público en Bogotá de 1995 a 2010. [tesis de pregrado], Bogotá, Pontificia Universidad Javeriana, Carrera de Ciencias Políticas.

SABATINI, F (2006) La segregación social del espacio en las ciudades de América Latina. Banco Interamericano de Desarrollo, Departamento de Desarrollo Sostenible, División de Programas Sociales. Recuperado del sitio (https://publications.iadb.org/handle/11319/5324)

SALAZAR, J. (2003). “¿Que hemos aprendido del espacio público? En: En: Bogotá y lo público: construcción de lo público. Bogotá: Universidad de los Andes (pp. 69 -76)

SAMPIERI, R; FERNÁNDEZ-COLLADO, C \& BAPTISTA, P (2006). Metodología de la investigación. Cuarta Edición. México: McGraw Hill.

SENDRA, P; CARRASCAL, M \& GARCÍA, C (2012, 14 de marzo) "Metodologías de investigación y acción en el espacio público obsoleto" [ponencia], 4IAU $4^{\text {a }}$ Jornadas Internacionales sobre Investigación en Arquitectura y Urbanismo, Valencia.

VERGARA, A. ET AL. (2015). Espacio público en Latinoamérica: de la fragmentación espacial y la segregación social hacia la cohesión territorial. Nuevos retos a viejos problemas. Diuscussion Paper, Zentrum für internationale Entwicklungs- und Umweltgorschung, No 73.

YORI, C. ED. (2011). Espacio Público y Derecho a la Ciudad. Bogotá: Editorial Pontificia Universidad Javeriana.

ZAMBRANO, F. (2003) "La polisemia del espacio público" En: Bogotá y lo público: construcción de lo público. Bogotá: Universidad de los Andes (pp. 35-46) 